\title{
Latest Evidence on Sulfonylureas: What's New?
}

Lawrence A. Leiter

Received: January 29, 2020 / Published online: April 22, 2020

(C) The Author(s) 2020

\section{ABSTRACT}

This review addresses the question of the cardiovascular (CV) safety of sulfonylureas (SUs) in patients with type 2 diabetes mellitus (T2DM) when directly tested against comparator agents in $\mathrm{CV}$ outcome trials. Presented at a recent symposium entitled "SUs in the treatment of T2DM: a fresh look and new insights" held on Wednesday September 18, 2019 during the 55th Annual Meeting of the European Association for the Study of Diabetes (EASD) in Barcelona Spain, this review discusses the initial evidence that sparked concerns over the CV safety of SUs as well as more recent findings from large studies of SUs (i.e. ADVANCE, TOSCA.IT and CAROLINA trials), highlighting the differences in CV and hypoglycaemia risks among the various SUs. Finally, the impact of glycaemic control on CV outcomes is also discussed, where the data suggest that the recent positive $\mathrm{CV}$ outcomes with some antihyperglycaemic agents may have been driven in part by improved glycaemic control.

Enhanced Digital Features To view enhanced digital features for this article go to https://doi.org/10.6084/ m9.figshare.12030336.

L. A. Leiter $(\bowtie)$

Division of Endocrinology and Metabolism, Li Ka

Shing Knowledge Institute, St Michael's Hospital,

University of Toronto, Toronto, Canada

e-mail: Lawrence.Leiter@unityhealth.to
Keywords: Cardiovascular outcomes; Sulfonylureas; Type 2 diabetes mellitus

\section{Key Summary Points}

A review of the available evidence for patients with type 2 diabetes mellitus (T2DM) suggests that good glycaemic control is an important factor in reducing the risk of diabetes-related complications such as cardiovascular (CV) events and hypoglycaemia

There is no difference in CV risk between sulfonylureas (SUs) and agents such as pioglitazone or linagliptin, according to recent large randomised controlled trials (ADVANCE, TOSCA.IT, CAROLINA)

The risk of hypoglycaemia varies between SUs, with the lowest rates reported for gliclazide, although absolute risk of hypoglycaemia is low for the class as a whole

\section{INTRODUCTION}

The University Group Diabetes Program (UGDP), a study published 50 years ago, 
initially reported increased cardiovascular (CV) mortality in patients with type 2 diabetes mellitus (T2DM) treated with tolbutamide ( $1.5 \mathrm{~g} /$ day) versus standard or variable doses of insulin and placebo [1]. Subsequent studies seemed to suggest that sulfonylureas (SUs) may have a worse impact on $\mathrm{CV}$ outcomes than metformin [2, 3], but the data have been inconsistent and often used older SUs than the ones currently in use today $[4,5]$. This article critically reviews the initial evidence that sparked concerns over the CV safety of SUs as well as more recent findings from large studies of SUs, and examines the impact of glycaemic control on CV outcomes. This article is based on previously conducted studies and does not contain any studies with human participants or animals performed by the authors.

\section{INITIAL EVIDENCE SPARKING CONCERNS OVER CARDIOVASCULAR SAFETY OF SULFONYLUREAS}

The UGDP, which initially reported increased CV mortality in patients with T2DM treated with tolbutamide, was not conducted like a modern cardiovascular outcome trial (CVOT) the patients did not have similar baseline CV risks, the difference did not reach statistical difference and there were very few events $(<100)$ [1]. Therefore, this was an underpowered, poorly conducted study. Apparent confirmatory evidence was provided by a real-world study comparing the risk of cardiovascular disease (CVD) or death in patients treated with metformin or SUs [3]. While results suggested that patients treated with metformin did better (hazard ratio [HR] 1.16; 95\% confidence interval [CI] 1.08, 1.25), it is unknown whether this was because metformin was better, SUs were worse or, most likely, the patients were different (i.e. as a result of selection bias). The SPREAD-DIMCAD study, a randomised controlled trial (RCT) that examined the effects of glipizide (15-30 [mean 28.3] $\mathrm{mg} /$ day) versus metformin on CV outcomes in Chinese patients with T2DM and coronary artery disease, suggested that patients treated with metformin had better CV outcomes (43 vs 60 CV events; HR 0.54; 95\% CI $0.30,0.90 ; p=0.026$ ); however, this was a small study (metformin $n=156$, glipizide $n=148)$ and the numbers of events were low [2]. It is therefore difficult to put great weight on such a small study.

Among larger studies, the UKPDS33 study $(n=3041)$ showed no deleterious CV effect of SUs (chlorpropamide 100-500 mg/day, glibenclamide $2.5-20.0 \mathrm{mg} /$ day) compared with insulin or conventional therapy [5], although this study tested older SUs that are used less today. Various meta-analyses have also been published evaluating the CV risk with SUs. One such meta-analysis evaluating data from $30 \mathrm{SU}$ CV safety trials of at least 6 months duration ( $n=29,873)$ found no consistent association with the risk of major adverse cardiovascular events (MACE; Mantel-Haenszel odds ratio [MH-OR] 1.08; 95\% CI 0.86, 1.36; $p=0.52$ ) [4] although a small, but statistically significant, increase in mortality was observed with SUs (MH-OR 1.22; 95\% CI 1.01, 1.49; $p=0.047$ ).

It should be noted, however, that there is evidence of differences among the SUs, suggesting that it may be inappropriate to combine data from trials utilising different SUs. For example, results of a Danish real-world study in 107,806 patients suggested that certain SUs may increase mortality and CV morbidity while others do not [6]. Monotherapy with certain commonly used SUs (i.e. glimepiride, glyburide, glipizide and tolbutamide), but not gliclazide or repaglinide, appeared to be associated with increased mortality and CV risk versus metformin in patients both with and without previous myocardial infarction (MI) [6]. Another study examining all-cause and CV mortality risk among sulfonylureas showed a dramatically reduced risk of mortality with gliclazide relative to glyburide (glibenclamide), in contrast to the other SUs [7].

The ADOPT study examined the glycaemic durability of rosiglitazone, metformin and glyburide (2.5-15.0 mg/day) monotherapy, and showed better glycaemic durability (primary endpoint) with rosiglitazone versus metformin (between-group differences in glycated haemoglobin (HbA1c) $\quad-0.13 \%$; 95\% CI 
$-0.22 \%,-0.05 \% ; \quad p=0.002)$ and glyburide $(-0.42 \% ; 95 \%$ CI $-0.50 \%,-0.33 \% ; p<0.001)$ [8]. However, surprisingly, rates of investigatorreported vascular serious adverse events were lower with glyburide than with rosiglitazone (CVD $1.8 \%$ vs $3.4 \%$; congestive heart failure $0.2 \%$ vs $0.8 \%$; both $p<0.05$ ) or metformin [8]. At the time, the data were dismissed because of the small number of events despite being similar to the number of events in the aforementioned UGDP [1].

\section{CARDIO-RENAL OUTCOMES IN LARGE STUDIES OF SUS}

\section{ADVANCE Study}

The ADVANCE study was a landmark study comparing intensive versus standard glucose control, in which more than $90 \%$ of the 5571 patients randomised to intensive therapy were receiving gliclazide $(30-120 \mathrm{mg} /$ day as modified release) while approximately $57 \%$ of 5569 patients in the standard therapy group were receiving other SUs (Table 1) [9]. While this was not a formal CV safety study, it should be noted that the group where all patients were virtually receiving gliclazide had no higher $\mathrm{CV}$ risk than the group where only about half were on SUs (cumulative incidence of $\mathrm{CV}$ death, MI, stroke: HR $0.94 ; 95 \%$ CI $0.84,1.06 ; p=0.32$ ). Additional findings of the ADVANCE study included a significant $10 \%$ decrease in the primary endpoint of combined major macrovascular and microvascular events with intensive versus standard therapy $(p=0.01)$; a non-significant $6 \%$ decrease in major macrovascular events $(p=0.32)$; a significant $14 \%$ decrease in major microvascular events $(p=0.015)$; and a significant $21 \%$ reduced risk of nephropathy $(p=0.006)[9]$.

Examination of the renal outcomes in more detail revealed improvements not just in proteinuria, i.e. a 9\% reduction in new-onset microalbuminuria and a $30 \%$ reduction in macroalbuminuria (both $p \leq 0.012$ ), but also in harder kidney outcomes. End-stage renal disease (ESRD; defined as renal transplant or dialysis) was also reduced by $65 \%$ at the end of the original study with intensive versus standard therapy $(p=0.0017)$, and by $43 \%$ after an additional 5 years of follow-up $[10,11]$.

\section{TOSCA.IT Trial}

The TOSCA.IT study [12] enrolled patients who had been diagnosed with T2DM for at least 2 years, had an $\mathrm{HbA} 1 \mathrm{c}$ of at least $7.0 \%$ and at most $9.0 \%$, were aged $50-75$ years, were on at least $2 \mathrm{~g}$ of metformin per day, had a body mass index (BMI) of $20-45 \mathrm{~kg} / \mathrm{m}^{2}$ and had not experienced any acute $\mathrm{CV}$ events in the past 6 months (Table 1). The study used a simple design, with patients randomised to add-on pioglitazone or SUs. Metformin dosage was constant throughout the study (2-3 g/day). The investigators could choose the specific SU (glibenclamide $\quad 5-15 \mathrm{mg} / \mathrm{day}, \quad$ gliclazide $30-120 \mathrm{mg} /$ day or glimepiride $2-6 \mathrm{mg} /$ day), with most patients receiving gliclazide or glimepiride. The other randomised group received pioglitazone $15-45 \mathrm{mg}$ /day. The dose was titrated at the discretion of the investigators, based on the results of HbA1c and self-monitoring of blood glucose [12].

While it would have been expected that metformin + pioglitazone would have better glycaemic durability, examination of HbA1c levels over 5 years of follow-up showed that reductions in HbA1c with metformin + SUs were similar to those in the metformin + pioglitazone group [12]. Rates of moderate and severe hypoglycaemia (i.e. plasma glucose below $60 \mathrm{mg} / \mathrm{dL}$ ) were higher with SU-based therapy versus pioglitazone-based therapy (32.4\% vs $9.6 \%$ and $1.6 \%$ vs $0.1 \%$, respectively), but the absolute risk was actually quite small [12]. There was no difference between treatment groups in the primary outcome of the cumulative incidence of all-cause death, non-fatal MI, non-fatal stroke or urgent coronary revascularisation over 60 months of follow-up [12]. Unfortunately, as a result of recruitment challenges, there were fewer participants and events than planned, so the study was underpowered and was therefore terminated for futility after 5 years. While the results can therefore not be 
Table 1 Study design and outcomes of the ADVANCE, TOSCA.IT and the CAROLINA trial

\begin{tabular}{|c|c|c|c|c|}
\hline Study & Study design and patients & $\begin{array}{l}\text { Number of patients and } \\
\text { treatment }\end{array}$ & $\begin{array}{l}\text { Median } \\
\text { follow-up } \\
\text { duration }\end{array}$ & CV outcomes \\
\hline $\begin{array}{l}\text { ADVANCE } \\
{[9]} \\
\text { NCT00145925 }\end{array}$ & $\begin{array}{l}\text { Phase III RCT } \\
\text { Patients with T2DM } \\
\text { aged } \geq 55 \text { years with a } \\
\text { history of major } \\
\text { macrovascular or } \\
\text { microvascular disease } \\
\text { or } \geq 1 \text { other risk factor for } \\
\text { vascular disease }\end{array}$ & $\begin{array}{l}\text { Intensive control: gliclazide } \\
\text { MR } 30-120 \mathrm{mg} / \text { day } \\
\quad(n=5571) \\
\text { Standard control: other } \\
\text { SUs }(n=5569)\end{array}$ & 5 years & $\begin{array}{l}\text { Comparative risk with } \\
\text { intensive versus standard } \\
\text { therapy } \\
\text { Cumulative incidence of } \\
\text { CV death, MI, stroke: HR } \\
0.94 ; 95 \% \text { CI } 0.84,1.06 \\
(p=0.32) \\
\text { Significant decrease in major } \\
\text { macrovascular and } \\
\text { microvascular events } \\
(p=0.01) \\
\text { Non-significant decrease in } \\
\text { major macrovascular events } \\
(p=0.32)\end{array}$ \\
\hline $\begin{array}{l}\text { TOSCA.IT } \\
{[12]} \\
\text { NCT00700856 }\end{array}$ & $\begin{array}{l}\text { Randomised phase IV trial } \\
\text { Patients with T2DM aged } \\
50-75 \text { years with an } \\
\mathrm{HbA} 1 \mathrm{c} \text { of } 7.0-9.0 \% \text {, BMI } \\
20-45 \mathrm{~kg} / \mathrm{m}^{2} \text {, on } \\
\text { metformin } \geq 2 \mathrm{~g} / \text { day, and } \\
\text { had not experienced any } \\
\text { acute CV events in the past } \\
6 \text { months }\end{array}$ & $\begin{array}{l}\text { Add-on pioglitazone: } \\
15-45 \mathrm{mg} / \text { day } \\
(n=1535) \\
\text { Add-on SUs: glibenclamide } \\
5-15 \mathrm{mg} / \text { day }(n=24) \\
\text { glimepiride } 2-6 \mathrm{mg} / \text { day } \\
(n=723) \text { or gliclazide } \\
30-120 \mathrm{mg} / \text { day } \\
(n=745)\end{array}$ & 57.3 months & $\begin{array}{l}\text { First occurrence of all-cause } \\
\text { death, non-fatal MI, non- } \\
\text { fatal stroke or urgent } \\
\text { coronary revascularisation: } \\
\text { HR for add-on } \\
\text { pioglitazone vs } \\
\text { sulfonylurea } 0.96,95 \% \mathrm{CI} \\
0.74-1.26 \text { ( } p=0.79) \\
\text { Incidence of hypoglycaemia: } \\
\text { pioglitazone vs SU: } 10 \% \text { vs } \\
34 \%(p<0.0001)\end{array}$ \\
\hline $\begin{array}{l}\text { CAROLINA } \\
{[13,14]} \\
\text { NCT01243424 }\end{array}$ & $\begin{array}{l}\text { Multicenter, double-blind, } \\
\text { phase III RCT } \\
\text { Patients with early T2DM } \\
\text { with an increased CV risk } \\
\text { or established } \\
\text { complications }\end{array}$ & $\begin{array}{l}\text { Linagliptin } 5 \mathrm{mg} / \text { day } \\
\quad(n=3023) \\
\text { Glimepiride } 1-4 \mathrm{mg} / \text { day } \\
\quad(n=3010)\end{array}$ & 6.3 years & $\begin{array}{l}\text { Non-inferiority for CV } \\
\text { death, non-fatal MI, non- } \\
\text { fatal stroke for linagliptin } \\
\text { versus glimepiride: HR } \\
0.98 ; 95.47 \% \text { CI } 0.84,1.14 \\
(p<0.0001) \\
\text { Similar between-group risks } \\
\text { of CV mortality (HR 1.00; } \\
95 \% \text { CI } 0.81,1.24) \text {, non- } \\
\text { CV mortality (HR 1.00; } \\
\text { 95\% CI 0.66, 1.03) and all- } \\
\text { cause mortality (HR 0.91; } \\
\text { 95\% CI } 0.78,1.06)\end{array}$ \\
\hline
\end{tabular}

$B M I$ body mass index, $C I$ confidence interval, $C V$ cardiovascular, HbAlc glycated haemoglobin, $H R$ hazard ratio, $M I$ myocardial infarction, $M R$ modified release, $R C T$ randomised controlled trial, $T 2 D M$ type 2 diabetes mellitus, $S U$ sulfonylurea 
considered definitive, there was no suggestion of harm in the patients treated with SUs [12].

\section{CAROLINA Trial}

The most recently reported study is the CAROLINA trial, which was designed to assess the $\mathrm{CV}$ safety of linagliptin versus glimepiride in patients with early T2DM at increased CV risk (Table 1) [13]. Enrolled patients had T2DM, an HbA1c of $6.5-8.5 \%$ (treatment-naïve or treated with metformin and/or $\alpha$-glucosidase inhibitor) or $6.5-7.5 \%$ (on alternative T2DM therapy), and had a high risk of $\mathrm{CV}$ events, defined as at least one of the following: previous CV complications; evidence of end-organ damage; age at least 70 years; or at least two CV risk factors [13]. After a 2-week placebo run-in, patients were randomised to linagliptin $5 \mathrm{mg} /$ day or glimepiride $1-4 \mathrm{mg} /$ day, both in combination with standard of care for up to 6 years. The primary endpoint was 4P-MACE (i.e. CV death, non-fatal MI, non-fatal stroke or hospitalisation for unstable angina), while 3P-MACE (i.e. CV death, non-fatal MI or non-fatal stroke) was a key secondary endpoint [13].

Baseline assessment showed that $42 \%$ of enrolled patients had established CV disease, $37 \%$ displayed at least two defined CV risk factors and 40\% had suffered from T2DM for no more than 5 years [14]. In addition, $9 \%$ of patients were treatment-naïve, $83 \%$ were receiving metformin and none were receiving insulin. Again, there was no overall meaningful difference in HbA1c between linagliptin and glimepiride over 5 years of follow-up: weighted average mean difference up to week $256,0.00 \%$ (95\% CI $-0.05,0.05)$ [14]. This is contradictory to animal models, which suggested that dipeptidyl peptidase 4 (DPP4) inhibitors have protective effects on beta cells [15-17], and thus may have greater glycaemic durability than existing therapies.

With regard to $\mathrm{CV}$ outcomes, non-inferiority for 3P-MACE (CV death, non-fatal MI, non-fatal stroke) was observed for linagliptin versus glimepiride, with virtually superimposable curves (HR 0.98; 95.47\% CI 0.84, 1.14; $p<0.0001$ for non-inferiority, $p=0.76$ for superiority) [14].
Also, risks of CV mortality (HR 1.00; 95\% CI $0.81,1.24$ ), non-CV mortality (HR 1.00; 95\% CI $0.66,1.03$ ) and all-cause mortality (HR 0.91; $95 \%$ CI $0.78,1.06$ ) were not different between groups. Thus, this was the second recent study showing no increased CV risk with SUs.

While rates of hypoglycaemia were higher with glimepiride than with linagliptin (Table 2), it is important to note that the absolute risk of hypoglycaemia was quite small, even in the SUtreated patients [18]. It is also important to highlight that the SU used in the CAROLINA study was glimepiride, and that there are differences among SUs in the risk of hypoglycaemia, as discussed later.

\section{IMPACT OF GLYCAEMIC CONTROL ON SAFETY OUTCOMES}

It is also important to consider the glucoselowering ability of SUs relative to other drug classes. A recently published model-based metaanalysis of T2DM antihyperglycaemic agents examined the impact of 24 T2DM drugs from six drug classes on glycaemic control, weight change and hypoglycaemia risk [19]. The study included data from 229 randomised, controlled trials, 710 individual treatment arms and 121,914 patients. Somewhat greater HbA1c reduction was observed with the glucagon-like peptide 1 receptor agonists (GLP-1RAs), but HbA1c reduction was greater with gliclazide $(1.04 \%)$ than with DPP4 inhibitors $(0.58-0.72 \%)$, sodium-glucose transport protein 2 (SGLT2) inhibitors (0.65-1.01\%) and thiazolidinediones $(0.62-0.98 \%)$. While the risk of hypoglycaemia was generally greater with SUs than with the other drug classes, among the SUs the relative hypoglycaemia risk was significantly lower with gliclazide than with glimepiride, glyburide and glipizide (3.6 vs $8.9,10.2$ and 13.9 , respectively) [19].

Another study, the GUIDE trial, compared the change in HbA1c and incidence of hypoglycaemia with gliclazide MR30 (30-120 mg/day) versus glimepiride (1-6 mg/day), both as monotherapy and in combination with metformin in 845 patients with T2DM under conditions of everyday clinical practice [20]. 
Table 2 Risk of hypoglycaemia in the CAROLINA study [18]

\begin{tabular}{|c|c|c|c|c|}
\hline & \multicolumn{2}{|c|}{ Rates of hypoglycaemia, \% } & \multirow[t]{2}{*}{ HR (95\% CI) } & \multirow[t]{2}{*}{$p$ value } \\
\hline & Linagliptin & Glimepiride & & \\
\hline Any & 10.6 & 37.7 & $0.23(0.21,0.26)$ & $<0.001$ \\
\hline Moderate or severe & 6.5 & 30.9 & $0.18(0.15,0.21)$ & $<0.001$ \\
\hline Severe $^{\mathrm{a}}$ & 0.3 & 2.2 & $0.15(0.08,0.29)$ & $<0.001$ \\
\hline Hospitalisation due to hypoglycaemia & 0.1 & 0.9 & $0.07(0.02,0.31)$ & $<0.001$ \\
\hline
\end{tabular}

$C I$ confidence interval, $H R$ hazard ratio

${ }^{a}$ Hypoglycaemic event requiring the assistance of another person to actively administer carbohydrate, glucagon or other resuscitative actions

After a follow-up of 27 weeks (6 months), similar reductions from baseline were observed in HbA1c with gliclazide versus glimepiride $(1.1 \%$ vs $1.0 \%$ ), but rates of confirmed hypoglycaemia were lower $(3.7 \%$ vs $8.9 \%)$ with no severe hypoglycaemia reported.

Finally the recently published EasyDIA study, which evaluated the real-world efficacy of gliclazide MR60 (30-120 mg/day) as monotherapy, add-on therapy to metformin, or switch from SU/metformin in more than 7000 patients with T2DM, demonstrated a $1.8 \%$ reduction in $\mathrm{HbA} 1 \mathrm{c}$, with $46.2 \%$ and $65.3 \%$ of patients achieving a target of HbA1c no greater than $7 \%$ at 3 and 6 months, respectively [21]. Severe hypoglycaemia was reported in only four $(0.06 \%)$ patients.

The existence of outcome studies showing $\mathrm{CV}$ and renal benefits above and beyond glycaemic control does not mean that glycaemic control is not important. This is supported by the results of a Swedish cohort study $(N=271,174$ T2DM patients vs $1,355,870$ controls), which confirmed that glycaemic control remains the most important risk factor for $\mathrm{CV}$ disease [22]. The primary aim of the study was to evaluate the association between the excess risks of death and $\mathrm{CV}$ outcomes in patients with T2DM. The study showed that an HbA1c level outside the recommended target range was the strongest predictor of stroke and acute MI. Also, recent meta-regression analysis using data from 12 CVOTs of various antihyperglycaemic agents, as well as those comparing intensive with standard therapy, showed that the trials with the greatest $\mathrm{HbA1c}$ reduction had the lowest HR of MACE [23].

\section{CONCLUSIONS}

Early glycaemic control in patients with T2DM is associated with a long-lasting 'legacy' effect in reducing later complications. Recent large randomised controlled trials have not shown differences in CV risk of SUs versus pioglitazone or linagliptin. However, the risk of hypoglycaemia varies among the SUs and may be dose dependent. It is therefore important to study the effect on CV outcomes of the doses of SUs currently used in clinical practice. It should also be noted that the glycaemic durability of different SUs may affect their CV risk in patients with T2DM and therefore may be an important parameter that requires further attention in clinical trials. The recent positive CVOTs with some antihyperglycaemic agents may be partly due to differences in glycaemia, indicating that good glycaemic control is an important component of a comprehensive risk-reduction strategy in diabetes.

\section{ACKNOWLEDGEMENTS}

Funding. Servier Medical Affairs, France, funded the development and publication of this article, including the journal's Rapid Service Fee. 
Medical Writing and Editorial Assistance. The author would like to thank Andrea Bothwell, on behalf of Springer Healthcare Communications, who provided medical writing assistance with the first draft of this manuscript. This medical writing assistance was funded by Servier, France.

Authorship. The author meets the International Committee of Medical Journal Editors (ICMJE) criteria for authorship for this article, takes responsibility for the integrity of the work as a whole, and has given their approval for this version to be published.

Prior Presentation. This article was based on the presentation given by the author at the symposium "SUs in the treatment of T2DM: a fresh look and new insights" during the 55th Annual Meeting of the European Association for the Study of Diabetes (EASD) in Barcelona Spain, 2019.

Disclosures. Lawrence A. Leiter has received grants, research support and honoraria, and participated in speakers bureaus for AstraZeneca, Boehringer Ingelheim, Eli Lilly, GlaxoSmithKline, Janssen, Merck, Novo Nordisk, Sanofi and Servier.

Compliance with Ethics Guidelines. This article is based on previously conducted studies and does not contain any studies with human participants or animals performed by the authors.

Data Availability. Data sharing is not applicable to this article as no datasets were generated or analyzed during the current study.

Open Access. This article is licensed under a Creative Commons Attribution-NonCommercial 4.0 International License, which permits any non-commercial use, sharing, adaptation, distribution and reproduction in any medium or format, as long as you give appropriate credit to the original author(s) and the source, provide a link to the Creative Commons licence, and indicate if changes were made. The images or other third party material in this article are included in the article's Creative Commons licence, unless indicated otherwise in a credit line to the material. If material is not included in the article's Creative Commons licence and your intended use is not permitted by statutory regulation or exceeds the permitted use, you will need to obtain permission directly from the copyright holder. To view a copy of this licence, visit http://creativecommons.org/licenses/by$\mathrm{nc} / 4.0 /$.

\section{REFERENCES}

1. Meinert CL, Knatterud GL, Prout TE, Klimt CR. A study of the effects of hypoglycemic agents on vascular complications in patients with adult-onset diabetes. II. Mortality results. Diabetes. 1970;19(Suppl):789-830.

2. Hong J, Zhang Y, Lai S, et al. Effects of metformin versus glipizide on cardiovascular outcomes in patients with type 2 diabetes and coronary artery disease. Diabetes Care. 2013;36(5):1304-11.

3. Roumie CL, Hung AM, Greevy RA, et al. Comparative effectiveness of sulfonylurea and metformin monotherapy on cardiovascular events in type 2 diabetes mellitus: a cohort study. Ann Intern Med. 2012;157(9):601-10.

4. Monami M, Genovese S, Mannucci E. Cardiovascular safety of sulfonylureas: a meta-analysis of randomized clinical trials. Diabetes Obes Metab. 2013;15(10):938-53.

5. UK Prospective Diabetes Study (UKPDS) Group. Intensive blood-glucose control with sulphonylureas or insulin compared with conventional treatment and risk of complications in patients with type 2 diabetes (UKPDS 33). UK Prospective Diabetes Study (UKPDS) Group. Lancet. 1998;352(9131):837-53.

6. Schramm TK, Gislason GH, Vaag A, et al. Mortality and cardiovascular risk associated with different insulin secretagogues compared with metformin in type 2 diabetes, with or without a previous myocardial infarction: a nationwide study. Eur Heart J. 2011;32(15):1900-8.

7. Simpson SH, Lee J, Choi S, et al. Mortality risk among sulfonylureas: a systematic review and network meta-analysis. Lancet Diabetes Endocrinol. 2015;3(1):43-51. 
8. Kahn SE, Haffner SM, Heise MA, et al. Glycemic durability of rosiglitazone, metformin, or glyburide monotherapy. N Engl J Med. 2006;355(23): 2427-43.

9. ADVANCE Collaborative Group, Patel A, MacMahon $S$, et al. Intensive blood glucose control and vascular outcomes in patients with type 2 diabetes. N Engl J Med. 2008;358(24):2560-72.

10. Perkovic V, Heerspink HL, Chalmers J, et al. Intensive glucose control improves kidney outcomes in patients with type 2 diabetes. Kidney Int. 2013;83(3):517-23.

11. Zoungas S, Chalmers J, Neal B, et al. Follow-up of blood-pressure lowering and glucose control in type 2 diabetes. N Engl J Med. 2014;371(15): 1392-406.

12. Vaccaro O, Masulli M, Nicolucci A, et al. Effects on the incidence of cardiovascular events of the addition of pioglitazone versus sulfonylureas in patients with type 2 diabetes inadequately controlled with metformin (TOSCA.IT): a randomised, multicentre trial. Lancet Diabetes Endocrinol. 2017;5(11): 887-97.

13. Marx N, Rosenstock J, Kahn SE, et al. Design and baseline characteristics of the CARdiovascular Outcome Trial of LINAgliptin Versus Glimepiride in Type 2 Diabetes (CAROLINA®). Diab Vasc Dis Res. 2015;12(3):164-74.

14. Rosenstock J, Espeland M, Kahn SE, et al. The CAROLINA Trial-first results of the cardiovascular outcomes trial comparing linagliptin vs. glimepiride. American Diabetes Association (ADA) 79th Scientific Session San Francisco, CA, USA, 2019.

15. Takeda Y, Fujita Y, Honjo J, et al. Reduction of both beta cell death and alpha cell proliferation by dipeptidyl peptidase- 4 inhibition in a streptozotocin-induced model of diabetes in mice. Diabetologia. 2012;55(2):404-12.

16. Wu YJ, Guo X, Li CJ, et al. Dipeptidyl peptidase-4 inhibitor, vildagliptin, inhibits pancreatic beta cell apoptosis in association with its effects suppressing endoplasmic reticulum stress in $\mathrm{db} / \mathrm{db}$ mice. Metabolism. 2015;64(2):226-35.

17. Zhang X, Wang Z, Huang Y, Wang J. Effects of chronic administration of alogliptin on the development of diabetes and beta-cell function in high fat diet/streptozotocin diabetic mice. Diabetes Obes Metab. 2011;13(4):337-47.

18. Rosenstock J, Kahn SE, Johansen OE, et al. Effect of linagliptin vs glimepiride on major adverse cardiovascular outcomes in patients with type 2 diabetes: the CAROLINA randomized clinical trial. JAMA. 2019;322(12):1155-66.

19. Maloney A, Rosenstock J, Fonseca V. A model-based meta-analysis of 24 antihyperglycemic drugs for type 2 diabetes: comparison of treatment effects at therapeutic doses. Clin Pharmacol Ther. 2019;105(5):1213-23.

20. Schernthaner G, Grimaldi A, Di Mario U, et al. GUIDE study: double-blind comparison of oncedaily gliclazide MR and glimepiride in type 2 diabetic patients. Eur J Clin Invest. 2004;34(8):535-42.

21. Leiter LA, Shestakova MV, Trubitsyna NP, Piletic M, Satman I. Implementing an optimized glucoselowering strategy with a novel once daily modified release gliclazide formulation. Diabetes Res Clin Pract. 2016;112:50-6.

22. Rawshani A, Rawshani A, Franzen S, et al. Risk factors, mortality, and cardiovascular outcomes in patients with type 2 diabetes. $\mathrm{N}$ Engl J Med. 2018;379(7):633-44.

23. Giugliano D, Maiorino MI, Bellastella G, Chiodini $\mathrm{P}$, Esposito K. Glycemic control, preexisting cardiovascular disease, and risk of major cardiovascular events in patients with type 2 diabetes mellitus: systematic review with meta-analysis of cardiovascular outcome trials and intensive glucose control trials. J Am Heart Assoc. 2019;8(12):e012356. 